\title{
Regeneration Therapy in Furcation Defect
}

\author{
Neha Munjal ${ }^{1}$, Shalini Kapoor ${ }^{2}$, Amit Bhardwaj ${ }^{3}$, Gaurav Thakur ${ }^{4}$, Preeti Karhana ${ }^{5}$ \\ 1, 2, 3, 5 Department of Periodontology, SGT University, Gurgaon, Haryana, India. \\ ${ }^{4}$ Liberal Dental Care, Gurgaon, Haryana, India.
}

\section{INTRODUCTION}

One of the main objectives of periodontal therapy is to regenerate tissues lost as a result of periodontal disease.$^{1}$ Regeneration is the growth and differentiation of the new cells and intercellular substances to form its precursor or regeneration occurs through same type of tissue that has been destroyed from same type of precursor. It is a continuous-physiological phenomenon of new cells along with tissues which are constantly formed and manifested by mitotic activity in epithelium and connective tissue, new bone formation, and continuous cementum deposition. Histological and clinical studies have reported the potential of guided tissue regeneration (GTR) to regenerate alveolar bone, cementum and the periodontal ligament.2,3

The furcation area represents a unique periodontal site with specific anatomic and pathogenic characteristics and with important clinical and therapeutic implications. The progression of chronic inflammation during periodontitis may affect the bifurcation or trifurcation of multirooted teeth. Furcation morphology may restrict access for adequate debridement and root instrumentation and may have a reduced source of available cells and blood supply from the periodontal ligament and bone defect. One important factor for successful regeneration at furcation and nonfurcation sites is the amount of periodontium that remains apical and lateral to the defect. Coronal migration of cells originating from the periodontal ligament and bone marrow spaces is particularly critical to the healing outcome following periodontal regenerative procedures in furcation defects.

One of the most important indications for GTR is class II furcation lesion in mandibular molars and interproximal defects. Clinical observations of GTR have shown more favourable outcomes in mandibular class III furcation and facial class II maxillary defects compared to limited success in other class II or class III defects. ${ }^{4}$ Clinical studies have shown that GTR can improve the response of class II furcation defects to therapy by means of reduction in pocket size, gain in clinical attachment levels and filling of bone defect. ${ }^{5}$ The regeneration of class II furcation lesion, although possible, is not considered a totally predictable procedure, especially in terms of complete bone filling.

One of the first regenerative technologies tested in the treatment of furcation defects was root conditioning with either citric acid or tetracycline. The rationale was that acid conditioning of a previously affected root surface would cause demineralisation of the exposed cementum and dentin, thereby exposing the collagen fibrils, and facilitating the adhesion of a blood clot and the subsequent migration of fibroblasts for the development of a new connective tissue attachment (fibrin linkage). The fragile nature of the interface between the coagulum and root surface at early-healing time points made wound stabilisation and protection imperative if successful regeneration was to be achieved.6,7
Corresponding Author: Dr. Shalini Kapoor, Department of Periodontology, Faculty of Dental Science, SGT University, Gurgaon, Haryana, India. E-mail:

shalinikapoor_fds@sgtunivertsity.org

DOI: $10.14260 /$ jemds/2021/233

How to Cite This Article:

Munjal N, Kapoor S, Bhardwaj A, et al. Regeneration therapy in furcation defect. $J$ Evolution Med Dent Sci 2021;10(15):10911094, DOI: 10.14260/jemds/2021/233

Submission 20-10-2020,

Peer Review 25-01-2021,

Acceptance 02-02-2021,

Published 12-04-2021.

Copyright (C) 2021 JEMDS. This is an open access article distributed under Creative Commons Attribution License [Attribution 4.0 International (CC BY 4.0)] 
Results of several studies suggested that regenerative outcomes in the treatment of furcation defects can be excellent only if the healing environment under the membrane is well protected by the flaps during healing and these barrier membranes are not exposed and contaminated. Under these circumstances, at 2 weeks, the furcation defect is filled with immature connective tissue containing different areas some rich in mesenchymal cells, with others containing mostly granulation tissue rich in inflammatory cells and vascular structures. This granulation tissue is subsequently replaced with mature connective tissue and bone. The chances of assuring the coronal positioning of the flap and its stability over the barrier membrane depended mostly on the size of the furcation defects and the shape of the surrounding alveolar bone.

Various biological and biomimetic substances, (material reproducing one or more natural phenomenon within a biological situation) have also been tested in experimental studies to assess their regenerative capability in furcation lesions. The biomimetic concept has been evaluated by testing the regenerative effect of enamel matrix proteins (enamel matrix derivative) The use of recombinant human platelet derived growth factor in combination with guided tissue regeneration showed improved regenerative outcomes in Class II and Class III furcation defects. The histologic outcomes suggested that the regenerative potential of the recombinant human platelet-derived growth factor-BB-demineralised freeze-dried bone allograft combination promoted new bone, cementum and periodontal ligament. 8 The present article emphasizes on regeneration of compromised teeth with nova bone graft and platelet rich fibrin (PRF) membrane in class III furcation defect.

\section{PRESENTATION OF CASE}

A 48-year-old male patient reported to the Out Patient Department (OPD) of the Department of Periodontology and Oral Implantology with a chief complaint of pain in the lower right back region since 20 days. Pain was mild and intermittent in nature, which aggravated on mastication. On intra-oral examination tooth was tender on percussion with grade I mobility in relation to lower right first molar teeth with a deep periodontal pocket on the mesial surface of the first molar. On radiographic examination vertical bone loss was evident on the mesial root of lower permanent right first molar with furcation involvement (Grade III).

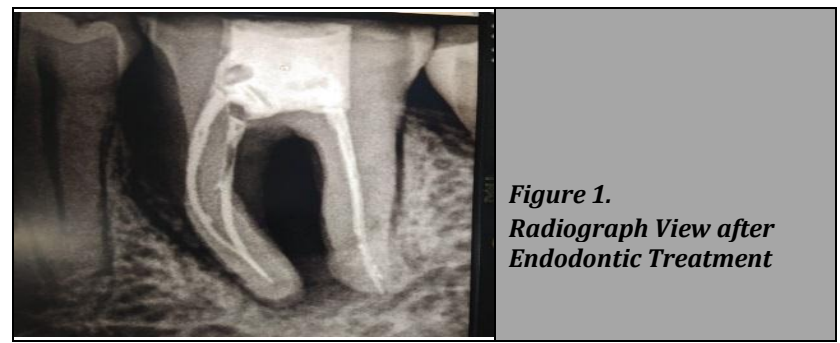

Based on clinical and radiographic finding the case was diagnosed as "endo-perio lesion" with primary periodontic component. Based on the diagnosis, intentional root canal therapy was done with respect to 36 followed by hemi section of mesial root with placement of bone graft and PRF as a membrane was used and placement of crown after 5 months. (Figure 1)
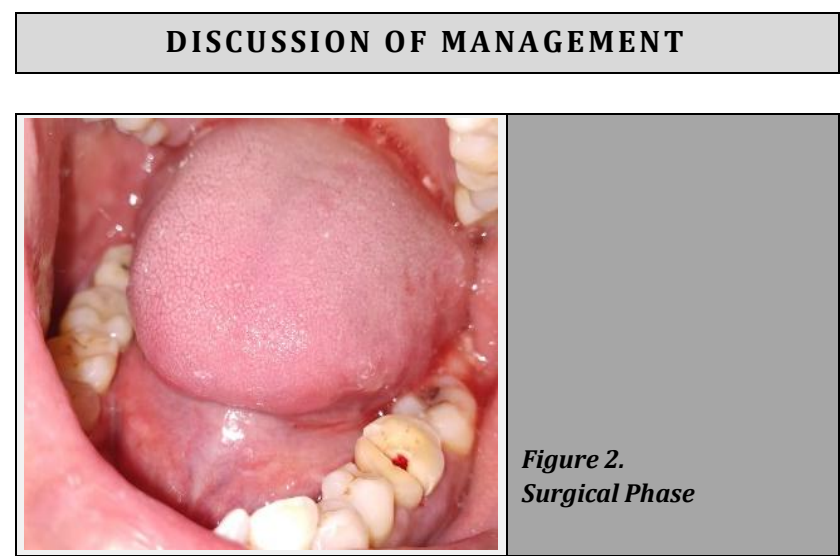

Figure 2. Surgical Phase
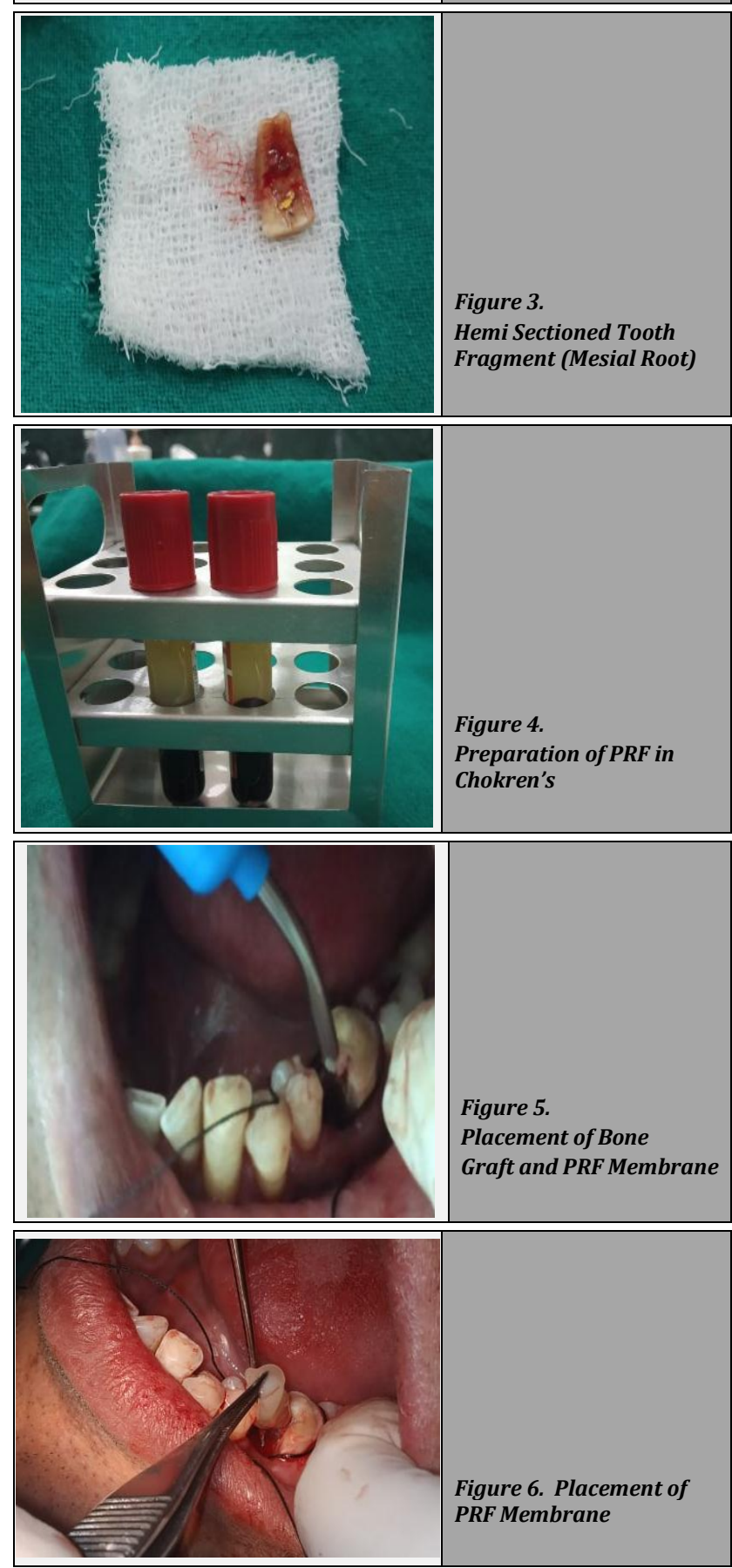

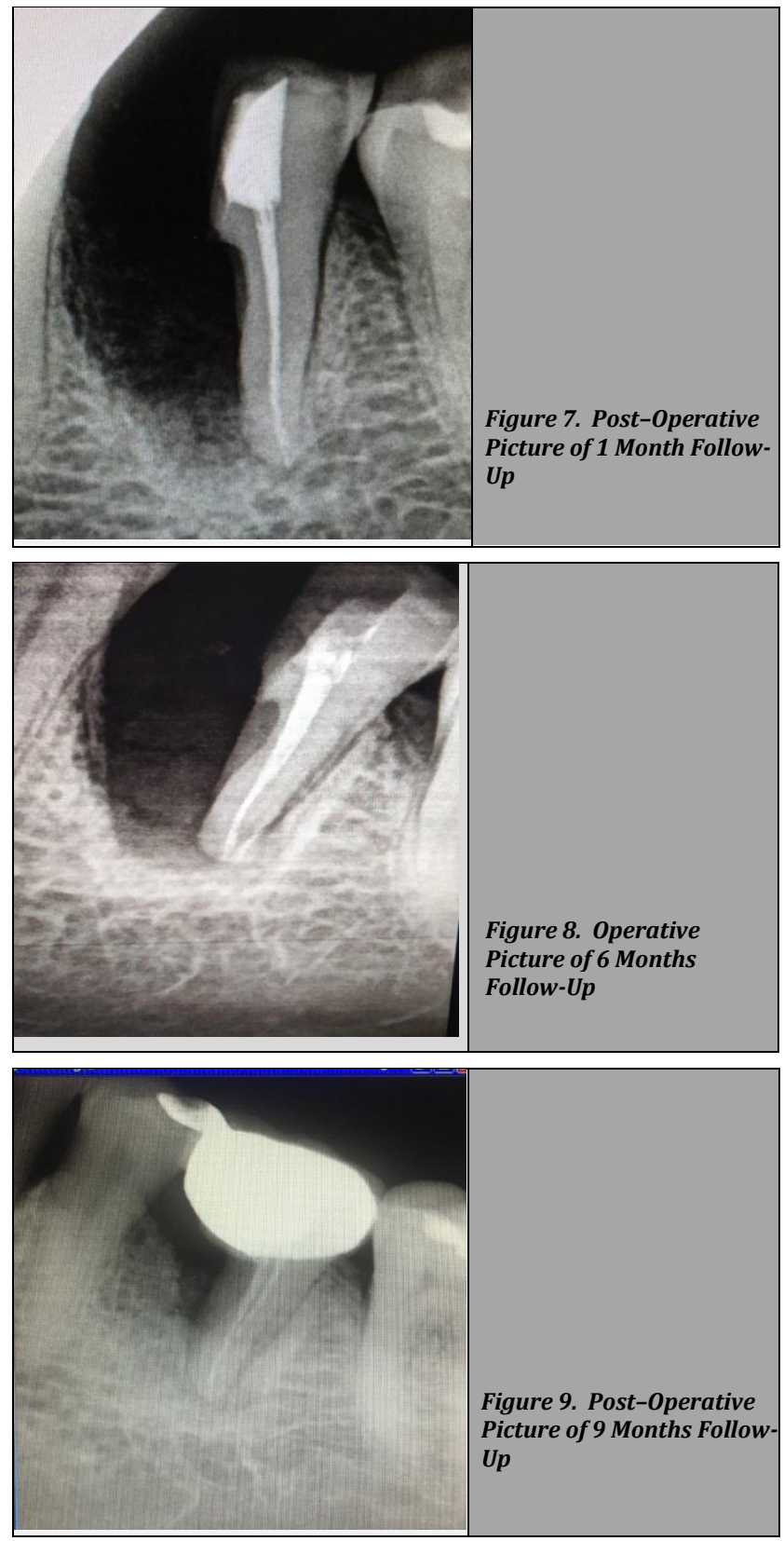

\section{Surgical Procedure}

Complete treatment plan was explained to the patient, after getting the informed consent. Under local anesthesia, surgical exposure of the flap, a crater like bony defect along the mesial root was visible. All the granulation tissue was removed with Gracey curettes (Hu-Friedy) to expose the bone. The vertical cut method was used to cut out the crown with mesial root. A long shank tapered fissure carbide bur was used to make vertical cut toward the bifurcation area. A fine probe was passed through the cut to ensure separation. The mesial half was extracted atraumatically and the socket was irrigated adequately with sterile saline and tetracycline. Scaling and root planning of the root surfaces, which became accessible on removal of mesial root was done. After removing the mesial root bone graft was placed along with PRF barrier membrane.

The occlusal table was minimised to redirect the forces along the long axis of the distal root. Radiographs showed the well retained distal root and extraction socket of the mesial root. After 1 month, healing of the tissues was evident. Hemisection of mesial root was done along with platelet rich fibrin membrane (PRF) followed by placement of NovaBone Putty-CMF (cranio-maxillofacial defects), as shown in Figure 5.

\section{Post-0perative Instructions}

Patient was asked to maintain good oral hygiene. The furcation area especially, to be kept very clean, because sites with minimal or no gingival inflammation have consistently better regenerative responses than sites with poor plaque control. Prescription for analgesic (ibuprofen, 600 mg every 6 - 8 hours for pain) and amoxycillin (thrice daily for 5 days) were given.

Follow up done at $7^{\text {th }}$ day and suture was also removed at first week post operatively. At 1 month recall visit, healing was uneventful with the absence of mobility. Radiographic success observed at 15 days, then after 1 and 3 months of recall visit indicated the absence of the periodontal ligament widening and bone formation at an extraction site. Healing of treated tooth was uneventful at recall visits. Pre-operative and postoperative pictures are shown below.

\section{DISCUSSION}

The regenerative therapy of furcation lesions may warrant the following conclusions. An abundance of studies and several systematic reviews with meta-analyses have demonstrated efficacy of guided tissue regeneration therapy for the regenerative treatment of furcation defects. Guided tissue regeneration therapy generally results in significantly higher vertical defect fill in class II furcation involvement of mandibular and maxillary molars when compared with open flap debridement.

Therapeutic strategies of teeth with furcation involvement should include the option of resective treatment. This case report shows the treatment of a periodontally compromised tooth by multidisciplinary treatment approach. The success of the hemi section procedure depends on the supporting bone, the restorative treatment plan, and the oral hygiene of the patient. Regular periodontal maintenance and sufficient coronal restoration of the root resected teeth are important preconditions for long term survival.

Financial or other competing interests: None.

Disclosure forms provided by the authors are available with the full text of this article at jemds.com.

\section{REFERENCES}

[1] Caffesse RG, Nasjleti CE, Plotzke AE, et al. Guided tissue regeneration and bone grafts in the treatment of furcation defects. J Periodontol 1993;64(Suppl 11):1145-53.

[2] Luepke PG, Mellonig JT, Brunsvold MA. A clinical evaluation of a bioresorbable barrier with and without decalcified freeze - dried bone allograft in the treatment of molar furcations. J Clin Periodontol 1997;24(6):440-6.

[3] Bowers GM, Schallhorn RG, McClain PK, et al. Factors influencing the outcome of regenerative therapy in mandibular class II furcations: part I. J Periodontol 2003;74(9):1255-68. 
[4] Pontoriero R, Lindhe J. Guided tissue regeneration in the treatment of degree II furcations in maxillary molars. J Clin Periodontol 1995;22(10):756-63.

[5] Garrett S. Periodontal regeneration around natural teeth. Ann Periodontol 1996;1(1):621-66.

[6] Caffesse RG, Holden MJ, Kon S, et al. The effect of citric acid and fibronectin application on healing following surgical treatment of naturally occurring periodontal disease in beagle dogs. J Clin Periodontol 1985;12(7):578-90.
[7] Egelberg J. Regeneration and repair of periodontal tissues. J Periodontal Res 1987;22(3):233-42.

[8] Camelo M, Nevins ML, Schenk RK, et al. Periodontal regeneration in human class II furcations using purified recombinant human platelet-derived growth factor-BB (rhPDGF - BB) with bone allograft. Int J Periodontics Restorative Dent 2003;23(3):213-25. 